\title{
Prolegómenos para una interpretación del cortometraje documental Buscando el azul
}

Recibido: 02 de agosto de 2018

Aceptado: 10 de septiembre de 2018

Publicado: 28 de noviembre de 2018

\author{
Carlos Cornejo Quesada \\ ccornejoq@unmsm.edu.pe \\ Universidad Nacional Mayor de San Marcos (Perú)
}

\begin{abstract}
Resumen: Se proponen algunos elementos para la interpretación del contenido de los cortometrajes documentales producidos por Fernando Valdivia, particularmente Buscando el azul (2003), situándolo en el escenario de la tribu Bora. Este estudio recurrió a una metodología cualitativa de carácter básico, etnográfico y no-experimental, teniéndose en cuenta las técnicas para la recolección de datos empíricos, como la entrevista, la estilística textual (tema, asunto, argumento), el punto de vista y los procedimientos (fichajes de textualidad escrita). Este instrumento metodológico permitió trazar semejanzas y homologaciones del contenido del film y la comunidad tribal, circunscrita al universo amazónico peruano, obteniéndose algunos rasgos temáticos que ayudan a comprender y explicar las fuentes audiovisuales.
\end{abstract}

Palabras clave: Cortometraje documental, Amazonía, comunidad tribal, tribu Bora, Víctor Churay, Fernando Valdivia.

\begin{abstract}
Some elements are proposed for the interpretation of the content of the documentary short films produced by Fernando Valdivia, particularly Buscando el azul (2003), situating it on the stage of the Bora tribe. This study resorted to a qualitative methodology of basic, ethnographic and non-experimental nature, taking into account the techniques for the collection of empirical data, such as the interview, the textual stylistics (subject, subject, argument), the point of view; and the procedures (written textuality signings). This methodological instrument allowed making similarities and homologations of the content of the film and the tribal community, circumscribed to the Peruvian Amazonian universe, obtaining some thematic features that help to understand and explain the audiovisual sources.
\end{abstract}

Key words: Documentary Short Film, Amazonia, Tribal community, Bora Tribe, Victor Churay, Fernando Valdivia. 


\section{Aspectos preliminares}

Para algunos directores cinematográficos ha resultado tentador contar (como objeto de trabajo) con el escenario de la selva peruana, sea a través de documentales de largo (y corto) metraje, exposiciones expresadas (en menor o mayor medida) en costumbres, tradiciones, leyendas, mitos e historias aparentemente inverosímiles. Gran parte de estos tuvieron sus propios protagonistas que procedían de los pueblos indígenas. Este componente es una de las intencionalidades que orientan los cortometrajes de Fernando Valdivia: son los indígenas de estos pueblos los actores directos quienes participan en el documental.

Para abordar el contenido de las obras de Valdivia, se ha propuesto una metodología de análisis de carácter cualitativo, respondiendo a una estrategia etnográfica, no experimental, incidiendo en el proceso cultural de los pueblos indígenas de la Amazonía. Existe el afán de encontrar y mostrar personajes nativos para documentar las experiencias y las historias de las poblaciones Bora, Asháninka y Shipibo. De ahí que esta investigación cualitativa identifica vacíos, limitaciones y otros, pero también hace propuestas o sugerencias.

Los testimonios audiovisuales constituyen una forma de documentación de la realidad social, cultural y ambiental. Así, los cortometrajes de Valdivia se configuran como documentales de la vida amazónica, con un afán pedagógico por crear una organización que departa la enseñanza y aprendizaje del documental cinematográfico de los nativos de la región. Además, poseen una explicita intención de recibir los aportes de otras culturas y denunciar los abusos cometidos contra los pobladores indígenas amazónicos.

Valdivia es un documentalista audiovisual conocido, pero su producción fílmica no ha sido esclarecida críticamente. Una aproximación a su contenido permite una doble perspectiva de enfoque: interna y externa. La primera hace referencia al contenido del cortometraje documental y la segunda al contexto representado. Creemos que el cine documental de Valdivia transita por la realidad concreta, aunque la presencia del productor y del protagonista se hacen notables en el libreto, guion y hasta en la edición realizada por el propio Valdivia.

En este aspecto, los films realizados por Valdivia son poco distantes entre sí, configurando la representación documental como fiel a las formas y modo de vida de las tribus Bora, Asháninka y Shipibo, asentadas en la región amazónica. Sin embargo, esto trae a colación una serie de preguntas reflexivas: ¿las tribus amazónicas siempre están representadas documentalmente en los cortos o largometrajes que tienen como escenario la Amazonía peruana?, ¿las tribus (arriba mencionadas) difunden sus expresiones culturales y su identidad al ser representados documentalmente en la obra de Valdivia?

\subsection{Propósitos de la investigación}

- Conocer la visión indígena amazónica en los cortometrajes de Valdivia, especialmente en el documental Buscando el azul. 
- Demostrar si los indígenas amazónicos son capaces de narrar su propia historia, mitos y leyendas, considerando el presente como el pasado, representado en el mencionado cortometraje.

- Exponer el interés indígena por difundir su propia identidad, sin negar la existencia ni la relación de su etnia con el mundo exterior, especialmente en Buscando el azul.

\subsection{Justificación y viabilidad}

El cine amazónico peruano ha signado un hito en la historia del arte cinematográfico. Ha existido el interés por difundir la selva amazónica latinoamericana, presentando una variedad de culturas y subculturas alejadas del mundo "civilizado" contemporáneo. Sostenemos que los documentales fílmicos de Valdivia son una ventana abierta para visualizar, informar y sensibilizar al público peruano y extranjero acerca de esta realidad.

En ese sentido, Valdivia ha mostrado una labor pedagógica al establecer talleres de documentales $^{1}$ en Atalaya y Ucayali (Pucallpa), permitiéndole filmar tres documentales con participación de los pueblos indígenas amazónicos (Yine, Asháninca, Yanesha, Awajun, Shipibo-conibo, Amahuaca, Matsigenka y Nomatsigenka). Así, Valdivia busca comprender los procesos sociales de estas tribus, mostrando sus modos de vida, así como sus expresiones culturales como testimonio de una realidad sociocultural existente y que se expresa como registro en lo filmado, manteniendo una participación protagónica de los propios indígenas, reconociendo el aporte de la modernidad.

La viabilidad de esta propuesta está dada por: a) existir fuentes documentales cinematográficas de la Amazonía, además de las orales, bibliográficas, hemerográficas y visuales, testimoniando la representatividad documental de la realidad existente y la realidad representada en Buscando el azul y b) es posible formular un diseño cualitativo con una metodología que patentice las estructuras latentes (aun inéditas) y que resulta necesario conocerlas.

También existen ciertas limitaciones para ejecutar ágilmente esta propuesta, como la dificultad de acceder al visionado de los films de Valdivia y de otros cineastas documentalistas. Asimismo, la corroboración de los datos obtenidos de los cortometrajes con los de la realidad concreta de los Boras, Asháninkas y Shipibos. Todo esto con el fin de no sustraerse a una interpretación arbitraria y epidérmica.

1 Gracias al apoyo de instituciones como Share Amazónica, Wenner Green Foundation y la Universidad Católica Sedes Sapientiae. 


\subsection{Diseño metodológico, técnicas e instrumentos}

El diseño metodológico es básico, etnográfico y experimental. En una primera circunstancia, los datos documentales, escritos y/o visuales (correspondientes a la realidad concreta o fílmica) están propuestas por Valdivia en ocho películas. Gran parte de estos datos están referidos a personajes como escenarios ambientales sociales y culturales, revelando temáticas múltiples (Banks, 2010, p. 42).

Se han considerado los datos fílmicos referidos a los personajes del universo cultural (idioma, vestimenta, alimentación) de los Boras, Asháninkas y otros. Estos datos pertenecen al grupo étnico que identifica a cada película, posibilitando una relación entre estas. El diseño no experimental ha permitido la obtención y acercamiento a los datos que configuran la temática del cortometraje documental, pero también a otros datos cinematográficos.

Una de las técnicas de investigación que se utilizó para el presente trabajo es la recolección de datos fílmicos, basado en los contenidos de los cortometrajes de Valdivia, especialmente Buscando el azul. Se consideraron modalidades de fichaje (trascripción, resumen y comentarios), los cuales permitieron testimoniar y expresar los datos audiovisuales documentales, aparte de los referidos a los contextos sociales y culturales. En ese sentido, se utilizaron fichas de transcripción y de comentarios, los cuales permitieron el registro de libros, revistas y periódicos.

La búsqueda de datos implicó el acercamiento a las imágenes fílmicas, con el objetivo de conocer su contenido y su naturaleza, el ritmo e intensidad de las filmaciones instituidas en un corpus siempre abierto a la lectura. En estas circunstancias, lo audiovisual está conformada por las películas de Valdivia: Etnias (2001), Buscando el azul (2003), La travesía de Chumpi (2009), Shipibo, la película de nuestra memoria (2010), Iskobakebo, Un difícil reencuentro (2014), Pueblos amazónicos y cambio climático (2014), PucallpaCruzeiro do Sul ¿hacia dónde nos lleva? (2014), Inuya, río del Otorongo (2017) y Q'eros. Nuestra vida, nuestra herencia (2017). Se ha preferido el documental Buscando el azul, donde el protagonista principal sugiere ricos referentes contextuales, comprometiendo no solo a otras tribus selváticas, sino también a la ciudad de Lima.

La actividad etnográfica está expresada, organizada y comparada por los datos recogidos directamente de las fuentes escritas, orales, visuales y audiovisuales, a fin de objetivizar las relaciones de los datos obtenidos e interpretarlos para su comprensión y explicación de las películas mencionadas.

\section{Encuentro con la Amazonía}

El cine peruano, como en otros países latinoamericanos, ha experimentado obstáculos económicos, sociales y hasta políticos, evolucionando de manera diferente a la cinematografía de Estados Unidos, Francia e Italia. Los pioneros anónimos ("Catedral de Lima", "Camino a la Oroya", "Chanchamayo", etc.) abrieron el registro documental 
audiovisual de la realidad peruana: los camarógrafos de esa época recorrieron las regiones naturales, llevando sus pesados equipos fílmicos para registrar tomas de paisajes, ceremonias religiosas, fiestas, costumbres, ritos, obras públicas, entre otros.

Con respecto a la región amazónica, Clemente Alcalá y Francisco de Paula Secada adquirieron, en la plaza principal de Manaos, un terreno, donde instalaron un local para sus actividades fílmicas. El terreno pasó poco después a propiedad de Eduardo Fuller, quien instaló el primer cine comercial en Iquitos, con equipo fílmico adquirido en Francia. Este empresario se asoció a otro para establecer otras salas cinematográficas en Iquitos. En 1914 fenece toda una etapa de producciones francesas para dar paso a nuevos films en la región amazónica. Se registra el ingreso de las tropas peruanas que participaron en el conflicto bélico de Caquetá (Colombia), los carnavales realizados en esa década y la vida familiar y social de la ciudad de Iquitos (Bedoya, 2015).

Los filmes más conocidos de la selva peruana surgen a partir de la década del 1960, bajo la estela de Armando Robles Godoy: En la selva no hay estrellas (1967) sobresale la profunda soledad que vive el hombre embargado por el paisaje. En La muralla verde (1970) se muestra la lucha solitaria del hombre contra las fuerzas de la naturaleza. Otra de las aproximaciones cinematográficas al universo amazónico es el Viento del Ayahuasca (1983), Norah de Izcue. Ambientado en Iquitos, explora los efectos sagrados y alucinógenos de la mencionada planta. Socio de Dios (1987), de Francisco García, narra la historia de un empresario cauchero, señalado como responsable de la esclavitud indígena.

El reconocido director alemán Werner Herzog ofrece una primera mirada a la Amazonía con Aguirre, la cólera de Dios (1972), filmada en las regiones selváticas del Cusco y Ucayali. La película está centrada en un explorador español quien busca empecinadamente el legendario reino de El Dorado. En cambio, dos producciones extranjeras más recientes, como Holocausto caníbal (1980), de Ruggero Deodato, y The Green Inferno (2013), de Eli Roth, abordan las infortunadas incursiones de jóvenes exploradores, quienes se adentran en la jungla amazónica para encontrarse con tribus caníbales.

Aparte de la conocida Pantaleón y las visitadoras (1999), basada en la novela del escritor Mario Vargas Llosa, dentro del mainstream comercial, el peruano Luis Llosa rodó la película Anaconda (1997), donde un grupo de documentalistas enfrenta a una enorme serpiente. Cementerio General (2013), de Doria Fernández Mora, que tiene como escenario la ciudad de Iquitos. Dentro del género del horror-suspenso, destaca La cara del diablo" (2014), de Frank Pérez Garland.

El documentalista más especializado en la edición de films amazónicos fue Gianfranco Annichini, quien que destacó por su estética y profundidad reflexiva. Entre sus obras destacaron El hombre sólo (1985) y Radio Belén (1983), en donde existe un hábil manejo de colores y luces, como la tipificación de personajes de la selva peruana. Este cortometraje 
se centra en la historia de la mencionada emisora radial del puerto de Belén (Iquitos) ${ }^{2}$, difundiendo una pluralidad cultural y paisajista con un tono muy personal.

\section{La representación y la realidad en el film}

La representación puede interpretarse como "una puesta en escena" en su máximo acercamiento a la realidad o al enfoque distinto al que fue desarrollado. Lo evidente es que la representación es el lugar donde los espectadores reconocen lo representado y son capaces de testimoniar lo existente. Esta noción es comúnmente empleada en las obras literarias (teatro, novela, poesía), así como en el cine, la fotografía, la pintura, caricatura o en la representación de algún hecho o personaje o elemento de la naturaleza. Para esto se necesitan instrumentos de identificación que apoyen el resultado final, tales como la iluminación, el maquillaje, el vestuario, entre otros aspectos.

El cine documental (corto o largometraje) se manifiesta como una expresión que los espectadores se reconocen o imaginan. La representación entendida como "símbolo, imagen o imitación" en Buscando el azul es un concepto importante para comprender y explicar una realidad representada que se hace conocer. En los medios de comunicación de masas, es un imperativo para percibir la realidad más objetiva posible. En este sentido, el cine documental busca permanentemente la representación de la selva amazónica peruana, como en el caso de Radio Belén, que hace referencia a una radioemisora que refleja la realidad amazónica.

La representación es un concepto que vializa la realidad natural y la expresión sociocultural. En este caso, se habla de la representación de las tribus nativas de la Amazonía y su expresión en el cine documental de Valdivia. Claro está que existen algunas simbolizaciones en el film. En otros casos, la representación es directa, manifestándose como un documento de la realidad representada. Gran parte de los cortometrajes de Valdivia representan la realidad concreta.

\subsection{La representación catequística}

Con la llegada de los misioneros dominicos a la Amazonía peruana, aparecieron las primeras muestras cinematográficas, específicamente en la selva del Cusco. Fue el sacerdote Gerardo Fernández quien inició estos proyectos en Koribeni (Alto Urubamba). Lo hizo junto con su pariente, el sacerdote Wenceslao Fernández, al participar como protagonista en uno de los documentales.

Ambos sacerdotes filmaron Misiones dominicas en el Perú (1929) junto con los nativos de la misión. La obra cuenta la historia de unos misioneros que se extravían en la selva.

2 Fue presentado en 1986 en el Festival de Cannes. 
La aparición de Santa Rosa de Lima los guía y ayuda a fundar una misión en el lugar³. Asimismo, otras filmaciones de la orden (Joaquín Barrantes y Adolfo Torralba) se enfocaron en los mitos y costumbres de los pueblos machiguengas. Posteriormente, el padre Roberto Ávalos denunció la contaminación ambiental que sufría en ese entonces la región del Alto Urubamba.

La difusión de esta y otras cintas (realizadas en Ecuador) llevó a que otras órdenes religiosas siguiesen el derrotero trazado por los misioneros dominicos. La filmación de Guillermo Garland y Fray Bernardino Idoyaga (La conquista de la Selva) registró la flora y fauna selvática, conjuntamente con las actividades misioneras de los franciscanos.

\subsection{La representación turística}

Para Bedoya, citado por Valdivia (2016), Antonio Wong Rengifo es el pionero del cine loretano (p. 113). Sus 20 años de trabajo fílmico en Iquitos lo sitúan entre los fundadores del cine de la Amazonía peruana. Desde 1931 hasta inicios de 1950, su labor ha sido constante, filmando sucesos y escenas cotidianas ocurridas en los pueblos indígenas. En los cincuentas, se despliega la visión antrópica del "divulgacionismo", ofreciendo información científica de la región de manera didáctica, con una aproximación más fiel a la realidad de los nativos amazónicos.

\subsection{La autorrepresentación imperiosa}

A principios de la década de 1970, un grupo de cooperantes (liderados por Tom Arden) llegó a Pucallpa e iniciaron su apoyo a mujeres shipibo, a fin de fortalecer sus cualidades artesanales y sus aportes económicos al hogar. Arden notó los efectos de la sobrepesca que afectaban el equilibrio del lago Yarinacocha y la dieta en proteínas para los shipibos de la selva central. Es así que surge el denominado "Proyecto audiovisual Shipibo" (1973), que involucró la realización cinematográfica con participación activa de los shipibos ${ }^{4}$.

Los poblados Bora, Huitoto y Ocaina (de la cuenca del Ampiyacu, Colombia) fueron traídos al Perú en la década de 1930. Tras la reordenación territorial entre el Perú y su vecino del norte, los nativos pudieron incursionar en la artesanía, siendo los primeros en utilizar la fibra del árbol conocida como Llanchama, elaborando pulseras y, sobre todo, lienzos.

3 Fue estrenado el 6 de junio de dicho año en el Santuario de Santa Rosa y en el Palacio Presidencial. Al día siguiente, se expuso en el Teatro Forero de Lima, incluyéndose orquestas, cantos y poesía. Gracias a su resonancia en los medios de comunicación, la cinta fue llevada a la Universal de Misiones en Barcelona, proyectándose luego en otras ciudades y países (Valdivia, 2016).

4 Sin embargo, dicha experiencia fracasó en 1974. Los cooperantes se retiraron y los equipos de filmación fueran entregados a la comunidad selvática de San Francisco, que terminaron extraviándose, así como los productos de filmación. 
A través de sus pinturas, Víctor Churay Roque pudo narrar la historia de la región desde un punto de vista indígena, mostrando los abusos sufridos por su pueblo durante el periodo del boom cauchero. Posteriormente, junto con Valdivia, participó en la elaboración de Buscando el azul (2003), documental que terminó de editarse un año después del fallecimiento de Churay. A propósito del film, Valdivia sostiene que

si bien Víctor Churay no filmó ninguna de las imágenes de este documental ni participó de la edición, su contribución y sugerencias estuvieron para los contenidos fue significativa, siendo marcadamente bajo la premisa de mostrar la realidad indígena desde el punto de vista indígena, con su voz e imagen, en escenas íntimas y entrevistas espontáneas, incluso de sus cuadros. Podríamos afirmar que fue una sinergia entre la pintura y el cine para lograr expresar el sentir indígena (Valdivia, 2016).

\section{Fernando Valdivia y el cine amazónico}

\subsection{Creación e inicios de la Escuela de Cine Amazónico (ECA)}

En el 2010 se diseñó el primer borrador de lo que sería la Escuela de Cine Amazónico en la ciudad de Pucallpa (Ucayali). Se realizó mediante un diagnóstico comunicacional como línea de base, obteniendo como resultado el interés prioritario entre los indígenas del Ucayali sobre todo lo relacionado con la radio, limitando el tema audiovisual. Con apoyo de la Municipalidad Provincial de Coronel Portillo se inició el trabajo intensivo de difusión audiovisual con los "Jueves de cine amazónico" con temática amazónica, ambiental y humanista, tratando de sensibilizar a la población.

La ECA fue creada en 2013 con la participación de Fernando Valdivia, Katty Quío y Carlos Marín. La escuela se inició con talleres en los que se narraba la experiencia en el cine documental amazónico. Bajo la dirección de Valdivia, se han definido los objetivos de los talleres audiovisuales:

Queríamos contribuir a dar formación a los indígenas peruanos, a los no indígenas, a aquellos que tuvieran la intención de realizar alguna obra audiovisual por iniciativa propia y que estuviesen convencidos de la necesidad de autovisibilizarse, de dar más presencia a las identidades amazónicas en los espacios audiovisuales, sea internet, TV regional, auditorios y cines, queríamos contribuir con nuestra experiencia realizada en el documental, la ficción, el video educativo y los talleres donde ganamos experiencia. Para "rebelarse" teníamos que dar un primer paso (Valdivia, 2016).

La finalidad de la ECA es promover la realización audiovisual y cinematográfica entre ciudadanos de la Amazonía peruana para visibilizar, informar y sensibilizar sobre temas socioambientales contemporáneos amazónicos que requieren atención. En ese sentido, la difusión de los proyectos audiovisuales ayudaría a conocer la gran diversidad cultural de nuestro país, expresada en sus pueblos, sus idiomas y expresiones cotidianas. 
Apostamos por un cine que revele esta riqueza, que nos acerque a ella mediante historias nacidas en cada uno de nuestro pueblos, con propuestas descolonizadas, un cine que nos haga pensar y soñar, pero que también revele la dureza de construir nuestro destino en sociedades excluyentes, marcadas por paradigmas donde el consumo y el crecimiento parecen desplazar los ideales de ciudadanía y respeto por la vida (Valdivia, 2016).

Es necesario resaltar la interculturalidad dentro en la labor de la ECA, puesto que es un espacio donde no solo participan miembros de la ciudad de Pucallpa, sino también de otras regiones. Como combinación de la filosofía urbana con la indígena, esta heterogeneidad enriquece los procesos culturales, proponiendo perspectivas y formas de crear.

Al observarse el contenido de la mayoría de las películas ambientadas en la selva amazónica, resulta necesario documentar la cultura y ambiente del hombre amazónico, su presente y su pasado histórico. Los films de Valdivia se adaptan a las modalidades expositivas y observacionales del cine documental, intentando expresar la realidad de pueblos amazónicos desde una perspectiva externa, sin descartar el papel interactivo y participativo del director con los protagonistas del documental. Así, la visión del cineasta se combina con la autorrepresentación de las comunidades o grupos nativos o indígenas que participan comunitariamente mediante algún protagonista principal.

\subsection{Obra cinematográfica de Valdivia}

Egresado de la Universidad Nacional Mayor de San Marcos, Valdivia incursionó en el mundo cinematográfico, produciendo documentales acerca de las tribus amazónicas, tales como el Asháninka, Shipibo-conibo, Isconahua, Awajun, Wampis, Kichwa, Shawi, Kukama, Amahuaca, Matses, Boras, Huitoto, Guaraní y Elmhet. Sobre su extensa producción en torno a la vida amazónica, Valdivia reflexiona al respecto:

Ser capaces de hablar sobre nosotros mismos y nuestro entorno inmediato, mediante la ficción, el documental o cualquier otro género, es una necesidad urgente para el país y para nosotros mismos. ¿O acaso no se sienten ustedes cansados que otros terminen hablando o proyectando imágenes de nosotros, pensando por nosotros, construyendo frente al mundo nuestra identidad desde sus particulares subjetividades e intereses? Esto debe terminar y el documental es una de las formas más democráticas de autoproyectarnos frente al mundo (Subirana, 2015).

Con sus producciones documentales, Valdivia manifiesta la búsqueda y el mantenimiento de una identidad colectiva acerca de su cultura y protección de la misma, a partir de sus propios protagonistas, sin dejar de ser ajenos a los aportes de modernidad. 


\subsection{Aculturamiento en la obra de Valdivia}

La noción de aculturamiento proviene de la antropología cultural anglosajona, la cual permitió conocer, en mayor o menor medida, la cultura de las comunidades amazónicas. Precisamente su operatividad metodológica ha despertado el interés hacia la cultura amazónica (grupos Asháninka, Bora y Shipibo) que son objeto principal de los documentales de Valdivia.

Los contenidos de las películas de Valdivia hacen visible la búsqueda de historias antiguas de la comunidad, así como sus modos de vida en la actualidad (rituales, lenguas, gastronomía), resaltándose los contextos culturales del universo amazónico. En esta circunstancia, se hace notable el uso del idioma español en las tribus. El personaje de Buscando el azul, Víctor Churay, es bilingüe y reconoce la importancia del español en su comunidad, así como su lengua nativa, como parte de su cultura e identidad.

Asimismo, cada personaje principal de los documentales de Valdivia migran a las ciudades: Víctor Churay viaja a Lima para estudiar. Churay retorna varias veces a su comunidad Bora, encontrándose con su padre, un cacique que debate algunas ideas de su hijo. En ese intercambio de ideas y experiencias, Churay busca un valor cromático del color azul para representar la naturaleza.

Lo mismo hace el joven indígena Alexander en otro documental (que lleva su mismo nombre). Oriundo del distrito de Tavanina (provincia de Atalaya, Ucayali), llega a Lima para luego volver a la selva y seguir estudios universitarios, donde conoce a estudiantes de otras tribus. Algo semejante ocurre con Carmen Lorena Valeria, joven de 15 años de edad en el documental Ritual Yanesha para convertirse en mujer (2017), quien mantiene tradiciones y costumbres de sus ancestros, utilizando plantas curativas y rituales de su lugar de origen. En los rituales se imbrican canciones e insumos del lugar de naturaleza bilingüística (español-nomachiyengua).

En cuanto a Buscando el azul, el personaje principal está en la búsqueda de un valor cromático poco común. Desde este aspecto, mediante la simbolización del color azul, Churay busca un matiz cromático para la representación figurativa de la realidad selvática, haciéndose presente en el dibujo, las plantas, corteza de árboles y pieles de animales. Esta búsqueda valorativa del color azul tiene un afán estético, pero nunca llega totalmente a encontrarlo. La representación de la búsqueda del color azul tiene un carácter ficticio para el propio Churay.

\section{Referencias}

Alayza, C., Cortés, G., Hurtado, G., Mory, E. \& Tarnawiecki, N. (2013). Iniciarse en la investigación académica. Lima: Universidad Peruana de Ciencias Aplicadas.

Annichini, G. (5 de julio de 2011). Radio Belén [video de YouTube]. Recuperado de https://www.youtube.com/watch?v=1TSmI1iF2Kc 
Banks, M. (2010). Los datos visuales en investigación cualitativa. Madrid: Morata.

Bedoya, R. (2015). Amazonía en el cine peruano. Recuperado de http://www. paginasdeldiariodesatan.com/pdds/?cat $=295$

Bustamante, E. (2013). Modalidades de representación en tres documentales amazónicos peruanos. Contratexto, 21, 165-175. Recuperado de http://revistas.ulima.edu.pe/ index.php/contratexto/article/viewFile/39/35

Caballero, A. (2005). Guías metodológicas para los planes de tesis y maestría y doctorado. Lima: Editorial Ugraph.

Definición ABC (2018). Definición de cine. Recuperado de https://www.definicionabc. com/general/cine.php

Goldman, L. (1985). Marxismo y estructuralismo. México, DF: Amorrortu.

Guarín Martínez, O. (2012). Exploración, ciencia y espectáculo. La cinematografía sobre la Amazonia en la primera mitad del siglo XX. Revista Chilena de Antropología Visual, 20. Recuperado de http://www.rchav.cl/2012_20_art03_guarin.html\#basecon

Hernández Sampieri, R. (2014). Metodología de la investigación. México DF: McGraw-Hill.

Hvalkof, S. (Ed.). (2003). Sueños amazónicos... Un programa de salud indígena en la selva peruana. Copenhague: Fundación Karen Elise Jensen \& NORDECO.

Jensen, A. (1982). Mito y culto entre pueblos primitivos. México, DF: Fondo de Cultura Económica.

Kerlinger, F. (1975). Investigación del comportamiento. Técnicas y metodología. México, DF: Nueva Editorial Interamericana.

Lecarnaqué, C. (12 de mayo de 2015). La Amazonía peruana en el cine. Recuperado de http://elpirata.pe/2015/05/12/la-amazonia-peruana-en-el-cine/

León, E. (2013). 14,000 mil años de alimentación en el Perú. Lima: Universidad de San Martín de Porres.

Macera, P. \& Casanto, E. (2009). El poder libre Asháninca: Juan Santos Atahualpa y su hijo Josecito. Lima: Universidad de San Martín de Porres.

Marcuse, H. (1978). Cultura y sociedad. Buenos Aires: Editorial Sur.

Martínez, A. \& Merino, A. (2006). Discurso y Socialización en producciones cinematográficas infantiles. Revista Comunicar, 26, 125-130. Recuperado de http://www.redalyc.org/articulo.oa?id=15802619 
Marvin, H. (2009). Desarrollo de las teorías antropológicas. México, DF: Editorial Siglo XXI.

Milla Batres, C. (1986). Diccionario histórico y biográfico del Perú. Lima: Editorial Milla Batres.

Ministerio de Cultura del Perú (2016). Representación audiovisual y ciudadanía intercultural. Ponencias del conversatorio "Videando diversidad cultural". Recuperado de https://centroderecursos.cultura.pe/sites/default/files/rb/pdf/ Representacion-audiovisual-y-ciudadania-intercultural.pdf

Subirana, K. (19 de mayo de 2015). La selva peruana en el cine. Recuperado de http:// encinta.utero.pe/2015/05/19/la-selva-peruana-en-el-cine/

Valdivia, F. (octubre de 2016). Conversatorio con Fernando Valdivia. Facultad de Letras y Ciencias Humanas. Universidad Nacional Mayor de San Marcos.

Valdivia, F. (12 de mayo de 2017). Buscando el azul [video de YouTube]. Recuperado de https://www.youtube.com/watch?v=TfgsTXnB3Ys

Velasco, H. \& Díaz, A. (1997). La lógica de la investigación etnográfica. Madrid: Editorial Trotta. 